\title{
Prevalence of cervical spine degenerative changes in elderly population and its weak association with aging, neck pain, and osteoporosis
}

\author{
Xiao-Rong Wang ${ }^{1,2}$, Timothy C. Y. Kwok ${ }^{3,4}$, James F. Griffith ${ }^{1}$, Blanche Wai Man Yu ${ }^{3}$, Jason C. S. Leung ${ }^{3}$, \\ Yì Xiáng J. Wáng ${ }^{1}$
}

${ }^{1}$ Department of Imaging and Interventional Radiology, Faculty of Medicine, Prince of Wales Hospital, The Chinese University of Hong Kong, Hong Kong, China; ${ }^{2}$ Department of Radiology, Ningbo First Hospital, Ningbo 315000, China; ${ }^{3}$ JC Centre for Osteoporosis Care and Control, Faculty of Medicine, Prince of Wales Hospital, The Chinese University of Hong Kong, Hong Kong, China; ${ }^{4}$ Department of Medicine and Therapeutics, Faculty of Medicine, Prince of Wales Hospital, The Chinese University of Hong Kong, Hong Kong, China

Contributions: (I) Conception and design: YXJ Wáng; (II) Administrative support: BWM Yu, JC Leung; (III) Provision of study materials or patients: TCY Kwok, BWM Yu, JCS Leung; (IV) Collection and assembly of data: BWM Yu, JCS Leung; (V) Data analysis and interpretation: XR Wang, TCY Kwok, JF Griffith, YXJ Wáng; (VI) Manuscript writing: All authors; (VII) Final approval of manuscript: All authors.

Correspondence to: Dr. Yì Xiáng J. Wáng. Department of Imaging and Interventional Radiology, Faculty of Medicine, Prince of Wales Hospital, The Chinese University of Hong Kong, Hong Kong, China. Email: yixiang_wang@cuhk.edu.hk.

Background: To investigate the prevalence of MRI degenerative findings of cervical spine in elderly Chinese males and females.

Methods: From a general population sample, cervical spine T2 weighted sagittal MR images were acquired in 272 males (mean age: 82.9 \pm 3.83 ) and 150 females (mean age: 81.5 \pm 4.27 ). Images were interpreted and degenerative changes were classified. Study subjects were divided into younger group (group A, $\leq 81$ years) and older group (group B, >81 years). For neck pain, question was structured as 'during the past 12 months, bave you had any neck pain?'. Two hundred and fifty-two males and 134 females also had hip bone mineral density (BMD) measured.

Results: $98.1 \%$ subjects exhibited at least one degenerative change at one or more vertebral levels. The C5/6 level had the highest overall frequency for degenerative changes. Most of the degenerative changes were more common in females. The older female group had higher prevalence or higher severity of degenerative findings than the younger group. Eleven point four percent of the males and $20.6 \%$ of the females reported neck pain, and male subjects with neck pain tended to have slightly higher prevalence of cervical degenerative changes. There was a weak trend that osteoporosis was associated with a higher prevalence of spinal cord high signal and a higher prevalence of spinal canal stenosis.

Conclusions: The age-dependence of cervical spine degenerative changes was more notable in females. Subjects with neck pain and subjects with osteoporosis were weakly associated with higher prevalence of cervical degenerative changes.

Keywords: Cervical spine; degenerative changes; MRI; aging; neck pain

Submitted Jun 22, 2019. Accepted for publication Jun 28, 2019.

doi: $10.21037 /$ atm.2019.07.80

View this article at: http://dx.doi.org/10.21037/atm.2019.07.80 


\section{Introduction}

Neck pain is a major public health problem, both in terms of personal health and overall well-being as well as the associated expenses. In one meta-analysis, Fejer et al. reported the point, one year, and lifetime prevalence of neck pain was $7.6 \%, 37.2 \%$, and $48.5 \%$, respectively, with women experiencing more neck pain than men (1). Most cases of uncomplicated neck are assumed to result from muscle sprains and strains, ligamentous injuries, and spinal degenerative changes (2). MRI is commonly used to investigate the possible causes of neck pain; however, the association between MRI finding of cervical spine degenerative changes and neck symptoms remain not well defined (2-8). Cervical degenerative findings are common in asymptomatic subjects, particularly subjects aged 40 and older (3-7). Frequency and range of cervical spine degenerative findings in asymptomatic individuals are also highly age-dependent (6,9-12).

MRI of spine in general population is important for investigating age-related changes. Till now, dedicated MRI study of cervical spine degeneration in very old general population is lacking. With a population based sample, this study investigated the prevalence of MRI degenerative findings of cervical spine in elderly Chinese males and females. In addition, we aimed to answer these questions: (I) do elderly females have more prevalent or more severe cervical degenerations than age-match elderly males? (II) at the mean advanced age of $82 \mathrm{yrs}$, do cervical degenerations remain age-dependent? (III) are cervical MRI degenerative findings more common in subjects with neck pain? and (IV) is lower bone mineral density (BMD) status associated with more prevalence or severe cervical degenerations (13)?

\section{Methods}

This was a part of the year-14 follow-up study of osteoporotic fractures in men (MrOS) (Hong Kong) and osteoporotic fractures in women (MsOS) (Hong Kong) studies. At baseline, 2000 Chinese men and 2000 Chinese women $\geq 65$ years were recruited from the local communities from August 2001 to March 2003 (14-16). The recruitment criteria were established so that the study results from the cohort would be applicable to a broad population of similarly aged community-dwelling men and women. The project was designed primarily to examine the BMD of older Chinese adults prospectively for 4 years. All participants were community dwelling, able to walk without assistance, had no bilateral hip replacement and had the potential to survive the duration of a primary study based on their general medical health. No participants had a known malignancy or previous lumbar spine surgery. The study protocol was approved by the Chinese University of Hong Kong Ethics Committee. Written informed consent was obtained from all participants. The male and female study cohorts was followed at year-4 (1,519 males and 1,546 females) (17,18). During 2014-2017, a year-14 followup was carried out. Cervical spine MRI was performed in 272 males (mean: 82.9 \pm 3.83 yrs; range, $77-99$ yrs) and 150 females (mean: $81.5 \pm 4.27 \mathrm{yrs}$; range, $74-100 \mathrm{yrs}$ ). The sample selection for MRI was random with potential bias for more mobile subjects as they were more willing to participate.

MRI was performed using a Philips Achieva TX 3.0T scanner equipped with dual transmitter (Philips Healthcare, Best, The Netherlands). The subjects were scanned in supine position, with the body coil used as the radiofrequency signal transmitter and dedicated spine coil used as the signal receiver. Due to the constrain of the MRI machine time available for this population study, only T2 weighted sagittal images were acquired. The imaging parameters included: 2-D turbo spin echo sequence, $\mathrm{TR}=3,000 \mathrm{~ms}, \mathrm{TE}=120 \mathrm{~ms}$, flip angle=90, slice thickness $=3.5 \mathrm{~mm}$, and inter-slice gap $=0.4 \mathrm{~mm}, \mathrm{FOV}=270 \mathrm{~mm}$ $\times 189 \mathrm{~mm}$, Matrix $=340 \times 263, \mathrm{NEX}=1$. All MRI was performed in Saturday morning. The study was designed so that males would be examined firstly. Due to some logistical reasons in the course of the study, this Saturday morning MRI time became no longer available, thus at the close of this study more males were scanned than females. To match the female subject number, 152 males (mean: 82.2 \pm 3.93 yrs; range, 77-99 yrs) were randomly selected, and male data were analyzed based on all participant $(n=272)$ and the subgroup $(\mathrm{n}=152)$. It was noted that there was no overall difference between the whole group analysis and the subgroup analysis, therefore the whole male group data are presented in this study.

Cervical levels from C2-T1 were evaluated according to the criteria described in Table 1. Example of cervical degenerative abnormalities are shown in Figure 1. MRI reading was performed by a radiologist and a physiotherapist trained in reading spine MRI. Initially these two readers scored the MR images independently, then the results were compared. In cases of score results differed, the MR images were read again and consensus was reached. Distribution of degenerative changes at each 
Table 1 Evaluation and grading scheme for cervical spine degeneration

\begin{tabular}{|c|c|}
\hline Assessed items & Evaluation and grading \\
\hline Spine curvature & 0: normal; 1: straightened or kyphotic \\
\hline Spinal cord high signal & 0: normal signal; 1: spinal cord regional high signal \\
\hline Spinal canal stenosis & $\begin{array}{l}0 \text { : normal or minimal subarachnoid space narrowing; } 1 \text { : Anterior subarachnoid space to narrowed } \\
\text { by } \geq 50 \% \text { without compression of spinal cord; } 2 \text { : canal stenosis } \geq 50 \% \text { and with compression of } \\
\text { spinal cord }\end{array}$ \\
\hline Dorsal osteophyte & 0: none; 1: notable dorsal osteophyte \\
\hline Schmorl node & 0: none; 1: schmorl node exists \\
\hline Vertebral body compressive deformity & 0: normal or minimal vertebral height loss; 1 : estimated $>30 \%$ vertebral height loss \\
\hline
\end{tabular}

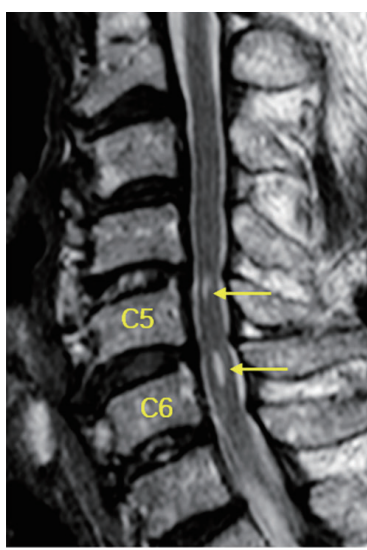

Spine cord high signal

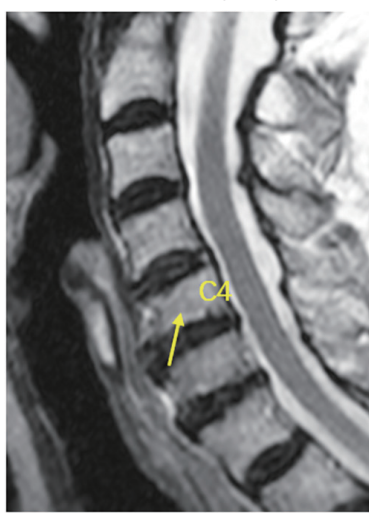

Compressive deformity

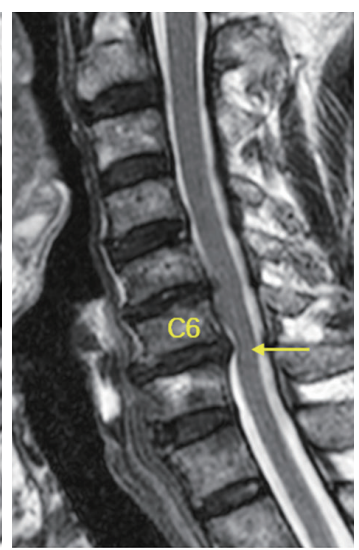

Canal stenosis

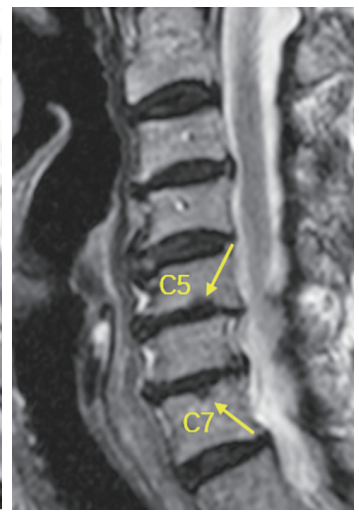

Schmorl nodes

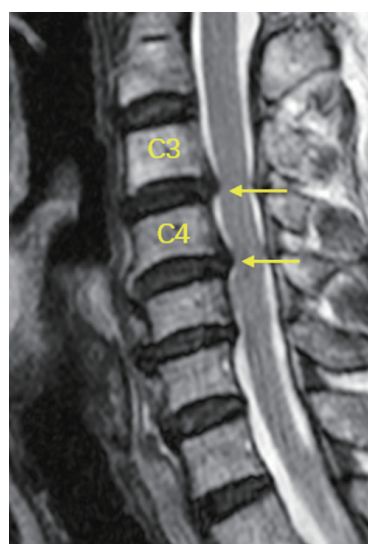

Disc protrusion

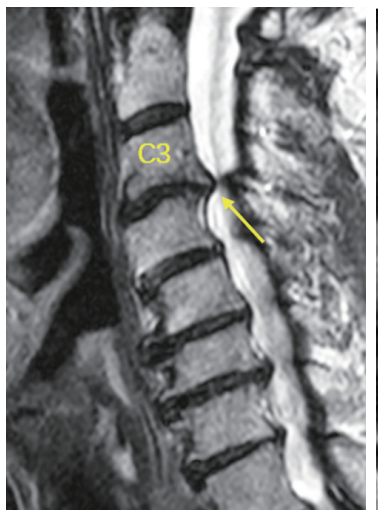

Posterior osteophyte

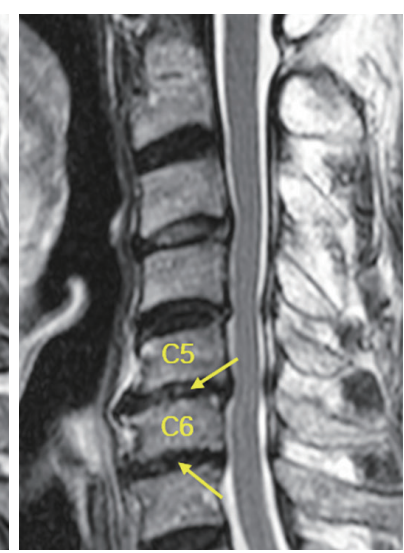

Disc space narrowing

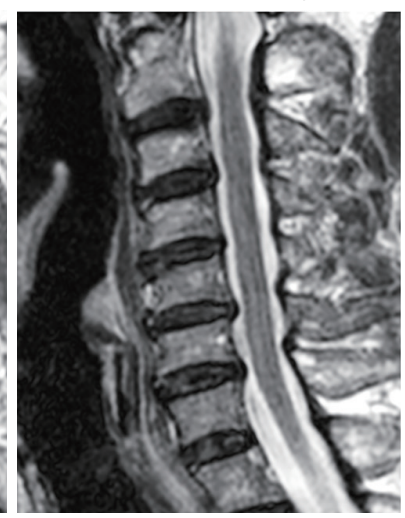

Loss of curvature

Figure 1 An illustration of cervical spine degenerative changes evaluated on MRI. 
Table 2 Prevalence of cervical spine degenerations among elderly males and females

\begin{tabular}{|c|c|c|c|c|c|}
\hline Assessed items & Evaluation/grading & Male [n=272] & Female $[n=150]$ & Total $[n=422]$ & $\mathrm{M}<\mathrm{F} ?$ \\
\hline Spinal cord high signal & Positive rate & $7.4 \%[20]^{\#}$ & $10.7 \%[16]$ & $8.5 \%[36]$ & Yes \\
\hline $\begin{array}{l}\text { Vertebra compressive } \\
\text { deformity }\end{array}$ & Positive rate & $8.1 \%[22]$ & $12.0 \%[18]$ & $9.5 \%[40]$ & Yes \\
\hline Dorsal osteophyte & Positive rate & $93.4 \%[254]$ & $95.3 \%[143]$ & $94.1 \%[397]$ & Yes \\
\hline Spine curvature & Positive rate & $66.2 \%[180]$ & $62.7 \%[94]$ & $64.9 \%[274]$ & No \\
\hline Spine canal stenosis & Grade-2 & $48.9 \%[133]$ & $51.3 \%[77]$ & $49.8 \%[210]$ & Yes \\
\hline \multirow[t]{2}{*}{ Disc space narrowing } & Grade-1 & $37.5 \%$ [102] & $28.7 \%[43]$ & $34.4 \%[145]$ & No \\
\hline & Grade-2 & $37.9 \%[103]$ & $42.7 \%[64]$ & $39.6 \%[167]$ & Yes \\
\hline Posterior disc protrusion & Class-2 & $5.5 \%[15]$ & $10.0 \%[15]$ & $7.1 \%[30]$ & Yes \\
\hline
\end{tabular}

$\%$, percentage of study subjects who had this degeneration; ", number in the bracket indicates number of study subjects who had this degeneration. $\mathrm{M}<\mathrm{F}$ : there is a trend that females had a higher prevalence than males.

vertebral level distribution, males $v s$. females comparison, age difference (group A: $\leq 81$ yrs old, group B>81 yrs), degenerative changes' association with neck pain prevalence and hip BMD status were evaluated. Males had 112 subjects in group A (age: 79.54 \pm 1.21 yrs; range, $77-81$ years) and 160 subjects in group B (age: $85.27 \pm 3.22 \mathrm{yrs}$; range, 82-99 years). Females had 87 subjects in group A (age: $78.65 \pm 1.37$ yrs; range, $75-81$ years) and 63 subjects in group B (age: $85.62 \pm 3.57$ yrs; range, $82-100$ yrs). For neck pain, question was structured as 'during the past 12 montbs, have you had any neck pain?', and 272 males and 150 females gave the answer. Two hundred and fifty-two males and 134 females had hip BMD measured (QDR4500W densitometer, Hologic Inc., Waltham, MA, USA), and the rest subjects did not attend BMD measurement.

The degenerative changes were classified according to 'by-each vertebral level' and 'by-subject'. With the 'by-each vertebral level' approach, for each subject, the existence and severity of degenerative changes were counted for the six vertebral levels. For the 'by- subject' approach, for each type of degenerative change, only the level with most severe score was counted. As 'by-each vertebral level' and 'bysubject' showed similar results (Tables $S 1, S 2$ ), in this study the 'by-subject' results are presented.

\section{Results}

The frequencies and of cervical degenerative findings are shown in Table 2. Out of the 422 subjects, 414 (98.1\%) exhibited at least one MRI degenerative finding at one or more vertebral levels. These degenerative changes tended to be more common in females; however, statistical significance was all not achieved. The degenerative findings' cervical level-specific and severity-specific data are shown in Figure 2. Spinal canal stenosis, disc space narrowing, and disc bulging/protrusion were common at c3/4, c4/5 and c5/6 levels, with $\mathrm{C} 5 / 6$ had the highest overall positive frequency. Spinal cord high signal was more common at C4/C5 levels. C5 vertebra had the highest prevalence of cervical compressive deformity.

The degenerative findings among the two age groups for males and females are shown in Figure 3 and Table S1. The female older group tended to have a higher prevalence of degenerative findings or a higher severity of degenerative findings, but this trend was less notable for the older male group.

Neck pain data were collected in 272 males and 150 females. In males, 241 subjects (age mean: 82.76 \pm 3.76 ; range, 77-99 yrs) did not had neck pain; 31 subjects (11.4\%) had neck pain (age mean: $84.13 \pm 4.14$; range, $77-95 \mathrm{yrs}$ ). 
Spinal cord high signal

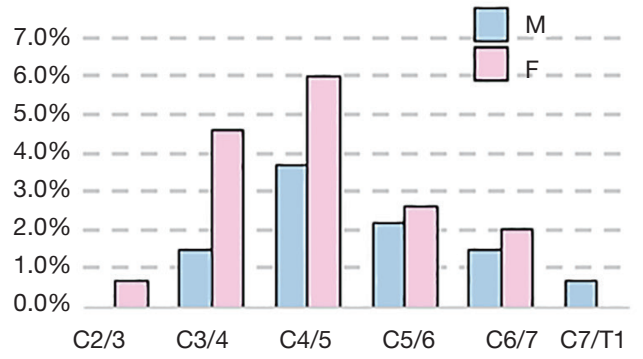

Disc space narrowing

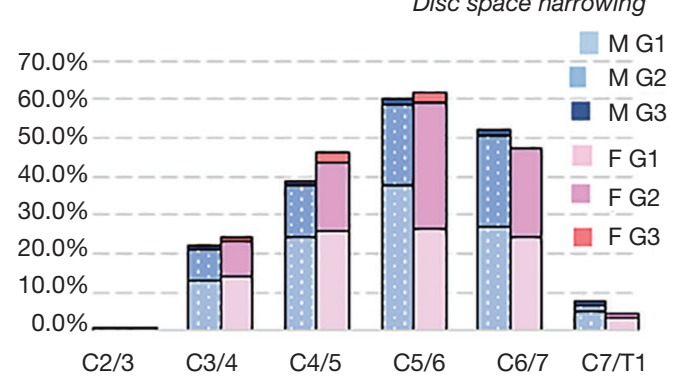

Dorsal osteophyte

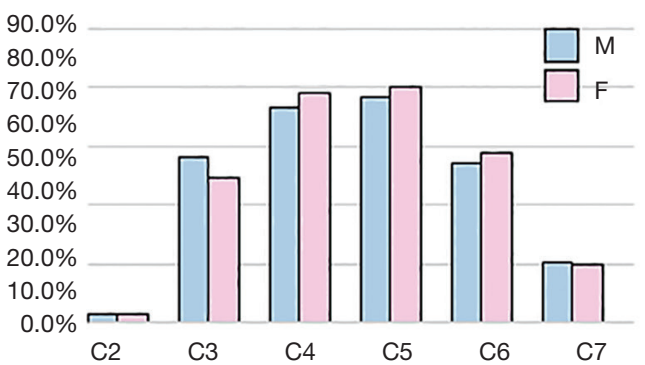

Schmorl node

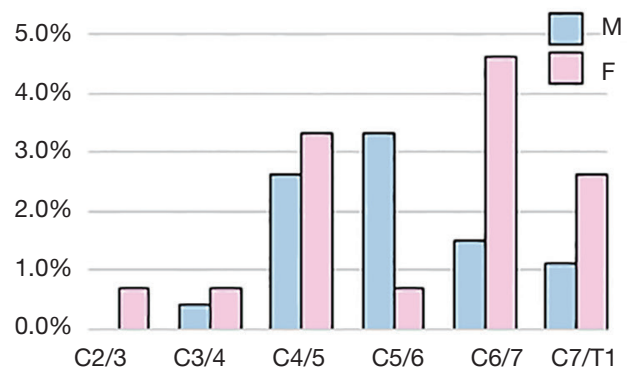

Cervical canal stenosis

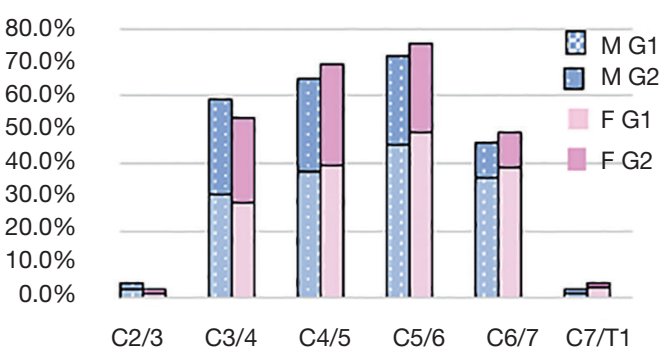

Posterior disc protrusion

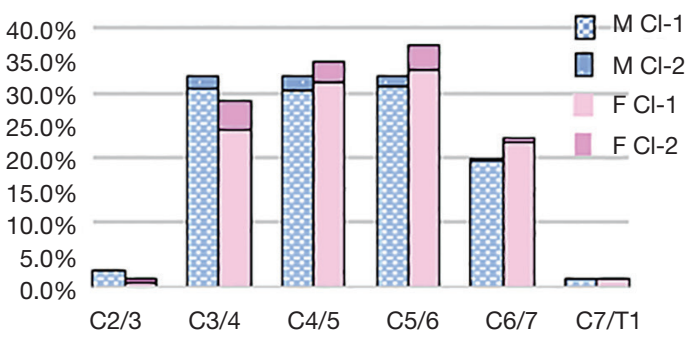

Vertebra compressive deformity

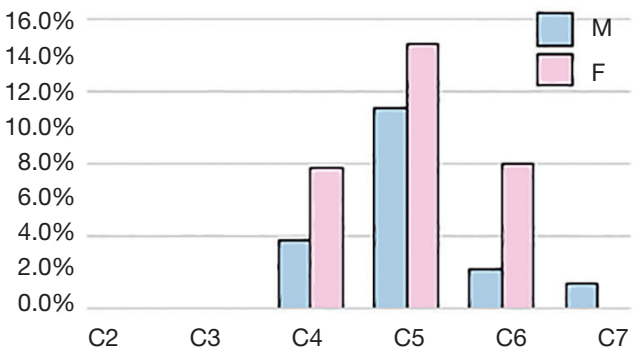

Figure 2 Cervical spine level-specific degenerative findings. Degenerative findings are overall slightly more frequent in females than in males, particularly for spinal cord high signal and vertebral body compressive deformity. M, males; F, females. G1, grade-1; G2, grade-2; G3, grade-3; Cl-1, class-1; Cl-2, class-2. 


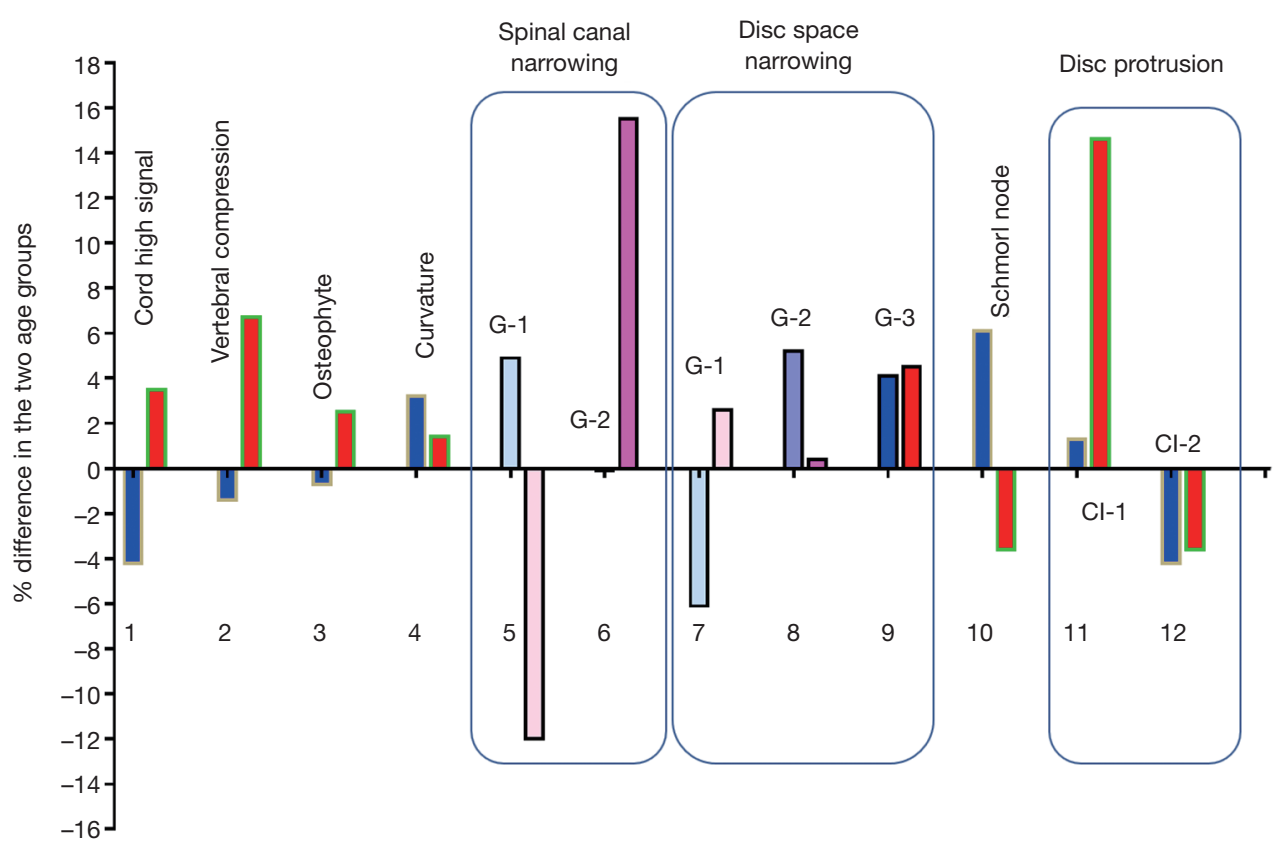

Figure 3 Age' effect on cervical spine degenerative findings. Positive values indicate higher prevalence in the older groups (B). Females' older group (pink or red colored bars) tends to consistently show positive values except grade-1 canal narrowing (but positive for grade-2 canal narrowing), Schmorl node and disc protrusion (class-2). Depending on the degeneration types, the trend for males (light blue or blue colored bars) is less consistent (more details see Table S1). G1, grade-1; G2, grade-2; G3, grade-3; Cl-1, class-1; Cl-2, class-2.

In females, 119 subjects (age: $81.44 \pm 4.32$; yrs; range, $74-100 \mathrm{yrs})$ did not had neck pain; 31 subjects $(20.6 \%)$ had neck pain (age: $81.65 \pm 4.20$ yrs; range, $76-93$ yrs). Table 3 shows an overall trend that subjects with neck pain had higher frequency of cervical spine degenerations which was more notable for males who had more sample size than females, with spinal canal stenosis being statistically more prevalent in male subjects with neck pain $(\mathrm{P}=0.025)$, and with spine curvature straightening and disc space narrowing being marginally more prevalent in male subjects with neck pain $(\mathrm{P}<0.1)$.

In males, there were 114 normal BMD subjects $(45.2 \%$, age mean: $82.13 \pm 3.57$; range, $77-97$ years), 121 osteopenia subjects (48.0\%, age mean: $83.94 \pm 4.02$; range, $78-99$ years), and 17 osteoporosis subjects (6.7\%, age mean: $83.47 \pm 2.87$ range: 79-90 years). In females, there were 25 normal BMD subjects (18.6\%, age mean: $80.48 \pm 3.28$; range, $77-88$ years), 78 osteopenia subjects $(58.2 \%$, age mean: $81.15 \pm 3.71$; range, $77-91$ years), and 31 osteoporosis subjects $(23.1 \%$, age: $84.45 \pm 5.46$; range, $77-100$ years). The association of cervical spine degenerative findings and osteopenic and osteoporosis is shown in Table S2. There was a trend that osteoporosis was associated with higher prevalence of spinal cord high signal and higher prevalence of spinal canal stenosis. For males, low BMD status was associated with a higher trend of vertebra compressive deformity prevalence.

\section{Discussion}

Although most acute neck pain episodes resolve spontaneously, more than a third of affected people have low grade symptoms or recurrences more than one year later $(1,2)$. Surgery is more effective than conservative treatment in the short term but not in the long term for most of these patients; moreover, early treatment does not have a meaningful impact on prognosis $(19,20)$. Variables that predict neck pain persistence include female sex, older age, presence of radiculopathy, higher baseline pain intensity, multiple pain sites, smoking, obesity, poor general health, and a variety of psychosocial factors (2). Cervical disc degenerations affect more than $80 \%$ of patients over 60 years without producing any symptoms (21). Degenerative changes can both be physiological aging changes and pathological changes $(21,22)$. As expected, this study confirms degenerative changes are extremely common in elderly subjects. In consistence with other reports of 
Table 3 Cervical spine degenerative change prevalence in study subjects with or without neck pain

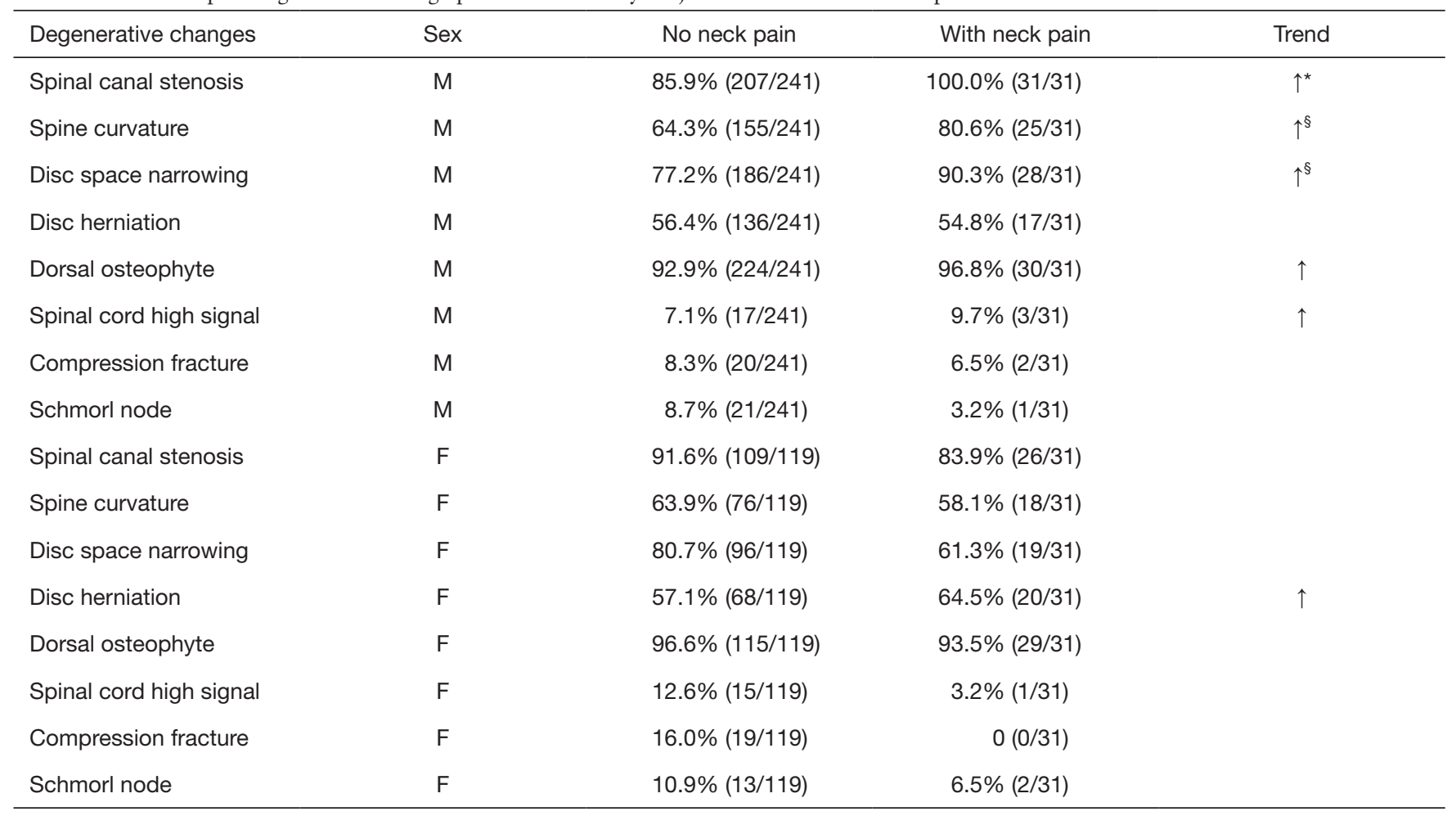

$\uparrow$, cervical spine degenerative change prevalence is higher in study subjects with pain than those without neck pain, being statistically significant or not significant. *, $\mathrm{P}<0.05 ;{ }^{\S}, \mathrm{P}<0.1$.

younger subjects $(6,11,23,24)$, spinal canal stenosis, disc space narrowing, and disc bulge/protrusion were common at $\mathrm{C} 3 / 4, \mathrm{C} 4 / 5$ and $\mathrm{C} 5 / 6$ levels, with the peak at C5/6 level. However, spinal cord high signal was more common at C4/C5 levels, both for males and females. It is generally considered that spinal cord high signal, which is associated with liquidation of spinal cord, is caused by spinal canal stenosis, particularly when impinged by protruded discs or osteophytes. Therefore our study shows a mismatch between the cervical level with the highest frequency of spinal canal stenosis and highest frequency of spinal cord high signal, this could partially be due to frequent rotation of the upper segment of cervical spine. This study shows, at advanced age, the older group ( $>81$ yrs old) still had higher prevalence of degenerative findings or higher severity of degenerative findings, and the age-dependence was more notable in females.

Our study also shows the cervical spine degenerative changes had higher frequency in elderly females than in elderly males; furthermore, females tended to have more severe grades of degeneration. In addition, while males and females had similar prevalence of spinal canal stenosis, spinal cord high signal is notably more prevalent in females, indicating females are prone to develop cervical myelopathy. Fejer et al.'s analysis noted that women report more neck pain than men, with on average the neck pain prevalence being $1 / 3$ higher in females than in males (1). This neck pain prevalence difference is likely be due to both differences in structural degeneration as well as difference in physiological mechanism. Women generally have a lower threshold of perception of pain and in reaction to it (25-27). However, in an evaluation of pain characteristics of adults 65 years of age and older referred to a tertiary pain care clinic, the older patients had relatively more physical problems concordant with their complaints, but fewer psychological factors contributing to disability than the younger pain patients (27). Recent evidences suggest relative estrogen deficiency may contribute to the accelerated lumbar disc degeneration and degenerative spondylolisthesis in postmenopausal women (28-33), which in turn is associated with increased prevalence of lower back pain (32). In the cervical spine, a similar trend may have been observed. In their study Matsumoto et al. (34) noted that disc degeneration was present in $17 \%$ of discs of men 
and $12 \%$ of those of women in their twenties, and $86 \%$ and $89 \%$ of discs of both men and women over 60 years of age. However, how long this 'post-menopause accelerated spine degeneration phase in women relative to men' lasts after menopause has not been determined. Gambacciani et al. (35) reported after menopause disc space shows a progressive decrease that almost entirely occurs in the first 5 to 10 years since menopause. However, our recent report in a 4-year follow-up study starting from a mean age of 72.5 years shows, there was a greater lateral thoracic and lumbar disc area loss in women than in men (36). That women have faster disc space narrowing than men even 20 years after menopause concurs with previous reports of Wóng et al. (16) and de Schepper et al. (37). The participants' age in this study is the oldest of the similar studies. This study tentatively suggests this 'accelerated spine degeneration' phase could last till $>81$ years old.

Despite the poor relationship between radiological abnormality and low back pain symptoms (38), low back pain is more common in subjects showing lumbar spine degenerative changes (39). For the relationship between cervical spinal degenerative changes and neck pain, this study tends to concur with this notion. On the other hand, this study does show the cervical spinal degenerative changes are very common in subjects without neck pain, even spinal cord high signal and vertebra compressive deformity were commonly noted in those subjects without neck pain. This study did not show an association between Schmorl nodes and neck pain. However, the overall prevalence of this sign was low. It is known that Schmorl nodes are mostly asymptomatic (40).

Compared with elderly males, elderly females are more likely to develop osteoporosis and osteoporotic vertebral facture, and senile osteoporosis is associated with lumbar disc degeneration (13). Osteoporosis may be an etiological factor in the development of disc degeneration with osteoporosis inducing loss of vertebral height, leading to instability, facet arthrosis, and disc degeneration. While thoracic/lumbar vertebra compressive deformity is commonly seen in clinical practice $(15,41)$, there are few research studies on this aspect for cervical spine. This study shows that low BMD status, being osteopenia, or osteoporosis, was associated with compressive fracture of cervical vertebra. This study confirms elderly females had higher prevalence of cervical vertebra compressive deformity than elderly males. For males, this study low BMD status was associated with spinal canal stenosis. A potential minor factor which could have interfered this observation is that females with osteoporosis were slightly older, however, there was no age difference between the three BMD groups in males. Schmorl's node is the herniation of nucleus pulposus through the cartilaginous and bony end plate into the body of the adjacent vertebra. Bone loss may predispose affected vertebrae to herniation of more disc material, exacerbating the condition. In this study, a trend is shown in males that lower BMD status was associated with higher frequency of Schmorl's node.

There are a number of limitations in this study. This study was not purposely designed for looking at cervical spine degenerations and statistical power was not initially determined; though for a MRI based study the study subjects number is large compared with many other reports (4-12). Thus we should more look at the trend of this study's results rather than look too much into the actual p-values. If the males and females show the same trends, then these trends are more likely to be real. Due to the higher prevalence of cervical spine degenerative changes and their ill-illuminated underlying causes, it is not surprising that the associations demonstrated in this study between degeneration and age, neck pain, or BMD were only weak. Statistical significance can be improved when the sample size is increased. In this study only T2 weighted sagittal images were acquired, this would negatively affect characterization of degenerative change of facet joints and foraminal stenosis.

In conclusion, this study showed cervical spine degenerative changes were very common in elderly population. The degenerative changes showed agedependency even at advanced age and this age-dependency tended to be more notable in females. Subjects with neck pain tended to have a higher prevalence of cervical degenerative changes, but the association was only weak. There was also a weak evidence to suggest that osteoporosis is associated with more prevalent cervical spine degenerations.

\section{Acknowledgments}

We thank Miss Hong-Yue Zhang for assistance in imagereading.

Funding: This study was partially supported by a grant from the Research Grants Council of Hong Kong SAR (Project no. SEG CUHK02).

\section{Footnote}

Conflicts of Interest: The authors have no conflicts of interest to declare. 
Ethical Statement: The authors are accountable for all aspects of the work in ensuring that questions related to the accuracy or integrity of any part of the work are appropriately investigated and resolved.

\section{References}

1. Fejer R, Kyvik KO, Hartvigsen J. The prevalence of neck pain in the world population: a systematic critical review of the literature. Eur Spine J 2006;15:834-48,

2. Cohen SP, Hooten WM. Advances in the diagnosis and management of neck pain. BMJ 2017;358:j3221.

3. Friedenberg ZB, Miller WT. Degenerative disc disease of the cervical spine: a comparative study of asymptomatic and symptomatic patients. J Bone Joint Surg 1963;45:1171-8.

4. Gore DR, Sepic SB, Gardner GM, et al. Neck pain: a long-term follow-up of 205 patients. Spine (Phila Pa 1976) 1987;12:1-5

5. Jónsson H Jr, Cesarini K, Sahlstedt B, et al. Findings and outcome in whiplash-type neck distortions. Spine (Phila Pa 1976) 1994;19:2733-43.

6. Lehto IJ, Tertti MO, Komu ME, et al. Age-related MRI changes at $0.1 \mathrm{~T}$ in cervical discs in asymptomatic subjects. Neuroradiology 1994;36:49-53.

7. Okada E, Matsumoto M, Ichihara D, et al. Aging of the cervical spine in healthy volunteers: a 10 -year longitudinal magnetic resonance imaging study. Spine (Phila Pa 1976) 2009;34:706-12.

8. Hill L, Aboud D, Elliott J, et al. Do findings identified on magnetic resonance imaging predict future neck pain? A systematic review. Spine J 2018;18:880-91.

9. Kong L, Tian W, Cao P, et al. Predictive factors associated with neck pain in patients with cervical disc degeneration: A cross-sectional study focusing on Modic changes. Medicine (Baltimore) 2017;96:e8447.

10. Matsumoto M, Okada E, Ichihara D, et al. Agerelated changes of thoracic and cervical intervertebral discs in asymptomatic subjects. Spine (Phila Pa 1976) 2010;35:1359-64.

11. Matsumoto M, Fujimura Y, Suzuki N, et al. MRI of cervical intervertebral discs in asymptomatic subjects. J Bone Joint Surg Br 1998;80:19-24.

12. Lee TH, Kim SJ, Lim SM. Prevalence of disc degeneration in asymptomatic Korean subjects. Part 2: cervical spine. J Korean Neurosurg Soc 2013;53:89-95.

13. Wáng YXJ. Senile osteoporosis is associated with disc degeneration. Quant Imaging Med Surg 2018;8:551-6.
14. Orwoll E, Blank JB, Barrett-Connor E, et al. Design and baseline characteristics of the osteoporotic fractures in men (MrOS) study - a large observational study of the determinants of fracture in older men. Contemp Clin Trials 2005;26:569-85.

15. Kwok AW, Gong JS, Wang YX, et al. Prevalence and risk factors of radiographic vertebral fractures in elderly Chinese men and women: results of Mr. OS (Hong Kong) and Ms. OS (Hong Kong) studies. Osteoporos Int 2013;24:877-85.

16. Wang YX, Griffith JF, Zeng XJ, et al. Prevalence and sex difference of lumbar disc space narrowing in elderly Chinese men and women: osteoporotic fractures in men(Hong Kong) and osteoporotic fractures in women (Hong Kong) studies. Arthritis Rheum 2013;65:1004-10.

17. Wáng YX, Deng M, Griffith JF, et al. Lumbar Spondylolisthesis Progression and De Novo Spondylolisthesis in Elderly Chinese Men and Women: A Year-4 Follow-up Study. Spine (Phila Pa 1976) 2016;41:1096-103.

18. Wáng YXJ, Che-Nordin N, Deng M, et al. Osteoporotic vertebral deformity with endplate/cortex fracture is associated with higher further vertebral fracture risk: the Ms. OS (Hong Kong) study results. Osteoporos Int 2019;30:897-905.

19. Vos CJ, Verhagen AP, Passchier J, et al. Clinical course and prognostic factors in acute neck pain: an inception cohort study in general practice. Pain Med 2008;9:572-80

20. Gore DR, Sepic SB, Gardner GM, et al. Neck pain: a long-term follow-up of 205 patients. Spine (Phila Pa 1976) 1987;12:1-5

21. Boden SD, McCowin PR, Davis DO, et al. Abnormal magnetic-resonance scans of the cervical spine in asymptomatic subjects. A prospective investigation. J Bone Joint Surg Am 1990;72:1178-84.

22. Adams MA, Roughley PJ. What is intervertebral disc degeneration, and what causes it? Spine (Phila Pa 1976) 2006;31:2151-61.

23. Okada E, Daimon K, Fujiwara H, et al. Twenty-year Longitudinal Follow-up MRI Study of Asymptomatic Volunteers: The Impact of Cervical Alignment on Disk Degeneration. Clin Spine Surg 2018;31:446-51.

24. Okada E, Matsumoto M, Ichihara D, et al. Aging of the cervical spine in healthy volunteers: a 10-year longitudinal magnetic resonance imaging study. Spine (Phila Pa 1976) 2009;34:706-12.

25. Turk DC, Okifuji A. Psychological factors in chronic pain: evolution and revolution. J Consult Clin Psychol 


\section{Page 10 of 10}

2002;70:678-90.

26. Rollman GB, Lautenbacher S. Sex differences in musculoskeletal pain. Clin J Pain 2001;17:20-4.

27. Mailis-Gagnon A, Nicholson K, Yegneswaran B, et al. Pain characteristics of adults 65 years of age and older referred to a tertiary care pain clinic. Pain Res Manag 2008;13:389-94

28. Wang YX, Griffith JF. Effect of menopause on lumbar disc degeneration: potential etiology. Radiology 2010;257:318-20

29. Wang YXJ. Postmenopausal Chinese women show accelerated lumbar disc degeneration compared with Chinese men. J Orthop Translat 2015;3:205-11.

30. Wang YXJ. Menopause as a potential cause for higher prevalence of low back pain in women than in age-matched men. J Orthop Translat 2016;8:1-4.

31. Gambacciani M, Pepe A, Cappagli B, et al. The relative contributions of menopause and aging to postmenopausal reduction in intervertebral disk height. Climacteric 2007;10:298-305.

32. Wáng YX, Wang JQ, Kaplar Z. Increased low back pain prevalence in females than in males after menopause age: evidences based on synthetic literature review. Quant Imaging Med Surg 2016;6:199-206.

33. Wang YXJ, Kaplar Z, Deng M, et al. Lumbar degenerative spondylolisthesis epidemiology: a systematic review with a focus on gender specific and age-specific prevalence. $\mathrm{J}$ Orthop Translat 2016;11:39-52.

34. Matsumoto M, Fujimura Y, Suzuki N, et al. MRI of

Cite this article as: Wang XR, Kwok TCY, Griffith JF, Yu BWM, Leung JCS, Wáng YXJ. Prevalence of cervical spine degenerative changes in elderly population and its weak association with aging, neck pain, and osteoporosis. Ann Transl Med 2019;7(18):486. doi: 10.21037/atm.2019.07.80

\section{Wang et al. Cervical spine degenerative changes in the elderly}

cervical intervertebral discs in asymptomatic subjects. J Bone Joint Surg Br 1998;80:19-24.

35. Gambacciani M, Pepe A, Cappagli B, et al. The relative contributions of menopause and aging to postmenopausal reduction in intervertebral disk height. Climacteric 2007;10:298-305.

36. Wáng JQ, Káplár Z, Deng M, et al. Thoracolumbar Intervertebral Disc Area Morphometry in Elderly Chinese Men and Women: Radiographic Quantifications at Baseline and Changes at Year-4 Follow-up. Spine (Phila Pa 1976) 2018;43:E607-14.

37. de Schepper EI, Damen J, van Meurs JB, et al. The association between lumbar disc degeneration and low back pain: the influence of age, gender, and individual radiographic features. Spine (Phila Pa 1976) 2010;35:531-6.

38. Wáng YXJ, Wu AM, Ruiz Santiago F, et al. Informed appropriate imaging for low back pain management: A narrative review. J Orthop Translat 2018;15:21-34.

39. Brinjikji W, Diehn FE, Jarvik JG, et al. MRI findings of disc degeneration are more prevalent in adults with low back pain than in asymptomatic controls: a systematic review and meta-analysis. Am J Neuroradiol 2015;36:2394-9.

40. Kyere KA, Than KD, Wang AC, et al. Schmorl's nodes. Eur Spine J 2012;21:2115-21.

41. Wáng YXJ, Ruiz Santiago F, Deng M, et al. Identifying osteoporotic vertebral endplate and cortex fractures. Quant Imaging Med Surg 2017;7:555-91. 
Table S1 Difference in prevalence of cervical spine degenerative findings between two age groups

\begin{tabular}{|c|c|c|c|c|c|}
\hline Degenerative changes & Sex & Grading & Group A: $79.16 \pm 1.36$ yrs & Group B: $85.37 \pm 3.32$ yrs & \\
\hline \multirow[t]{4}{*}{ Spinal cord high signal } & M & + Rate & $9.8 \%(11 / 112)$ & $5.6 \%(9 / 160)$ & \\
\hline & & & $2.2 \%(15 / 672)$ & $1.2 \%(11 / 960)$ & \\
\hline & $\mathrm{F}$ & + Rate & $9.2 \%(8 / 87)$ & $12.7 \%(8 / 63)$ & $\uparrow$ \\
\hline & & & $1.9 \%(10 / 522)$ & $3.4 \%(13 / 378)$ & $\uparrow$ \\
\hline \multirow[t]{4}{*}{ Vertebra compressive deformity } & M & + Rate & $8.9 \%(10 / 112)$ & $7.5 \%(12 / 160)$ & \\
\hline & & & $1.5 \%(10 / 672)$ & $1.4 \%(13 / 960)$ & \\
\hline & $\mathrm{F}$ & + Rate & $9.2 \%(8 / 87)$ & $15.9 \%(10 / 63)$ & $\uparrow$ \\
\hline & & & $1.9 \%(10 / 522)$ & $3.2 \%(12 / 378)$ & $\uparrow$ \\
\hline \multirow[t]{4}{*}{ Dorsal osteophyte } & M & + Rate & $93.8 \%(105 / 112)$ & $93.1 \%(149 / 160)$ & \\
\hline & & & $45.8 \%(308 / 672)$ & $48.8 \%(468 / 960)$ & \\
\hline & $\mathrm{F}$ & + Rate & $94.3 \%(82 / 87)$ & $96.8 \%(61 / 63)$ & \\
\hline & & & $43.9 \%(229 / 522)$ & $55.3 \%(209 / 378)$ & $\uparrow$ \\
\hline \multirow[t]{4}{*}{ Spine curvature } & M & + Rate & $64.3 \%(72 / 112)$ & $67.5 \%(108 / 160)$ & \\
\hline & & & - & - & \\
\hline & $\mathrm{F}$ & + Rate & $62.1 \%(54 / 87)$ & $63.5 \%(40 / 63)$ & \\
\hline & & & - & - & \\
\hline \multirow[t]{8}{*}{ Spine canal stenosis } & M & Grade-1 & $35.7 \%(40 / 112)$ & $40.6 \%(65 / 160)$ & $\uparrow$ \\
\hline & & & $25.2 \%(169 / 672)$ & $25.5 \%(245 / 960)$ & \\
\hline & & Grade-2 & $51.8 \%(58 / 112)$ & $46.9 \%(75 / 160)$ & \\
\hline & & & $17.7 \%(119 / 672)$ & $14.7 \%(141 / 960)$ & \\
\hline & $\mathrm{F}$ & Grade-1 & $43.7 \%(38 / 87)$ & $31.7 \%(20 / 63)$ & \\
\hline & & & $30.1 \%(157 / 522)$ & $23.0 \%(87 / 378)$ & \\
\hline & & Grade-2 & $44.8 \%(39 / 87)$ & $60.3 \%(38 / 63)$ & $\uparrow$ \\
\hline & & & $12.6 \%(66 / 522)$ & $20.4 \%(77 / 378)$ & $\uparrow$ \\
\hline \multirow[t]{12}{*}{ Disc space narrowing } & M & Grade-1 & $41.1 \%(46 / 112)$ & $35 \%(56 / 160)$ & \\
\hline & & & $17.41 \%(117 / 672)$ & $18.13 \%(174 / 960)$ & $\uparrow$ \\
\hline & & Grade-2 & $34.8 \%(39 / 112)$ & $40.0 \%(64 / 160)$ & $\uparrow$ \\
\hline & & & $9.38 \%(63 / 672)$ & $12.50 \%(120 / 960)$ & $\uparrow$ \\
\hline & & Grade-3 & $0.9 \%(1 / 112)$ & $5.0 \%(8 / 160)$ & $\uparrow$ \\
\hline & & & $0.15 \%(1 / 672)$ & $1.25 \%(12 / 960)$ & $\uparrow$ \\
\hline & $\mathrm{F}$ & Grade-1 & $27.6 \%(24 / 87)$ & $30.2 \%(19 / 63)$ & $\uparrow$ \\
\hline & & & $16.9 \%(88 / 522)$ & $14.6 \%(55 / 378)$ & \\
\hline & & Grade-2 & $42.5 \%(37 / 87)$ & $42.9 \%(27 / 63)$ & \\
\hline & & & $13.2 \%(69 / 522)$ & $15.3 \%(58 / 378)$ & $\uparrow$ \\
\hline & & Grade-3 & $3.4 \%(3 / 87)$ & $7.9 \%(5 / 63)$ & $\uparrow$ \\
\hline & & & $0.57 \%(3 / 522)$ & $1.85 \%(7 / 378)$ & $\uparrow$ \\
\hline \multirow[t]{4}{*}{ Schmorl node } & M & + Rate & $4.5 \%(5 / 112)$ & $10.6 \%(17 / 160)$ & $\uparrow$ \\
\hline & & & $0.74 \%(5 / 672)$ & $1.98 \%(19 / 960)$ & $\uparrow$ \\
\hline & $\mathrm{F}$ & + Rate & $11.5 \%(10 / 87)$ & $7.9 \%(5 / 63)$ & \\
\hline & & & $2.5 \%(13 / 522)$ & $1.6 \%(6 / 378)$ & \\
\hline \multirow[t]{8}{*}{ Posterior disc protrusion } & M & Class- 1 & $50 \%(56 / 112)$ & $51.3 \%(82 / 160)$ & \\
\hline & & & $20.7 \%(139 / 672)$ & $18.3 \%(176 / 960)$ & \\
\hline & & Class-2 & $8.0 \%(9 / 112)$ & $3.8 \%(6 / 160)$ & \\
\hline & & & $1.5 \%(10 / 672)$ & $0.63 \%(6 / 960)$ & \\
\hline & $\mathrm{F}$ & Class- 1 & $42.5 \%(37 / 87)$ & $57.1 \%(36 / 63)$ & $\uparrow$ \\
\hline & & & $17.4 \%(91 / 522)$ & $21.7 \%(82 / 378)$ & $\uparrow$ \\
\hline & & Class-2 & $11.5 \%(10 / 87)$ & $7.9 \%(5 / 63)$ & \\
\hline & & & $2.5 \%(13 / 522)$ & $1.9 \%$ (7/378) & \\
\hline
\end{tabular}

+ Rate, prevalence of the positive findings for degeneration; $\uparrow$, the older group shows a trend of higher + rate. Cells in italic: results as 'byintervertebral-level'. 
Table S2 Prevalence of cervical spine degenerative changes in normal BMD, osteopenia, and osteoporosis subjects

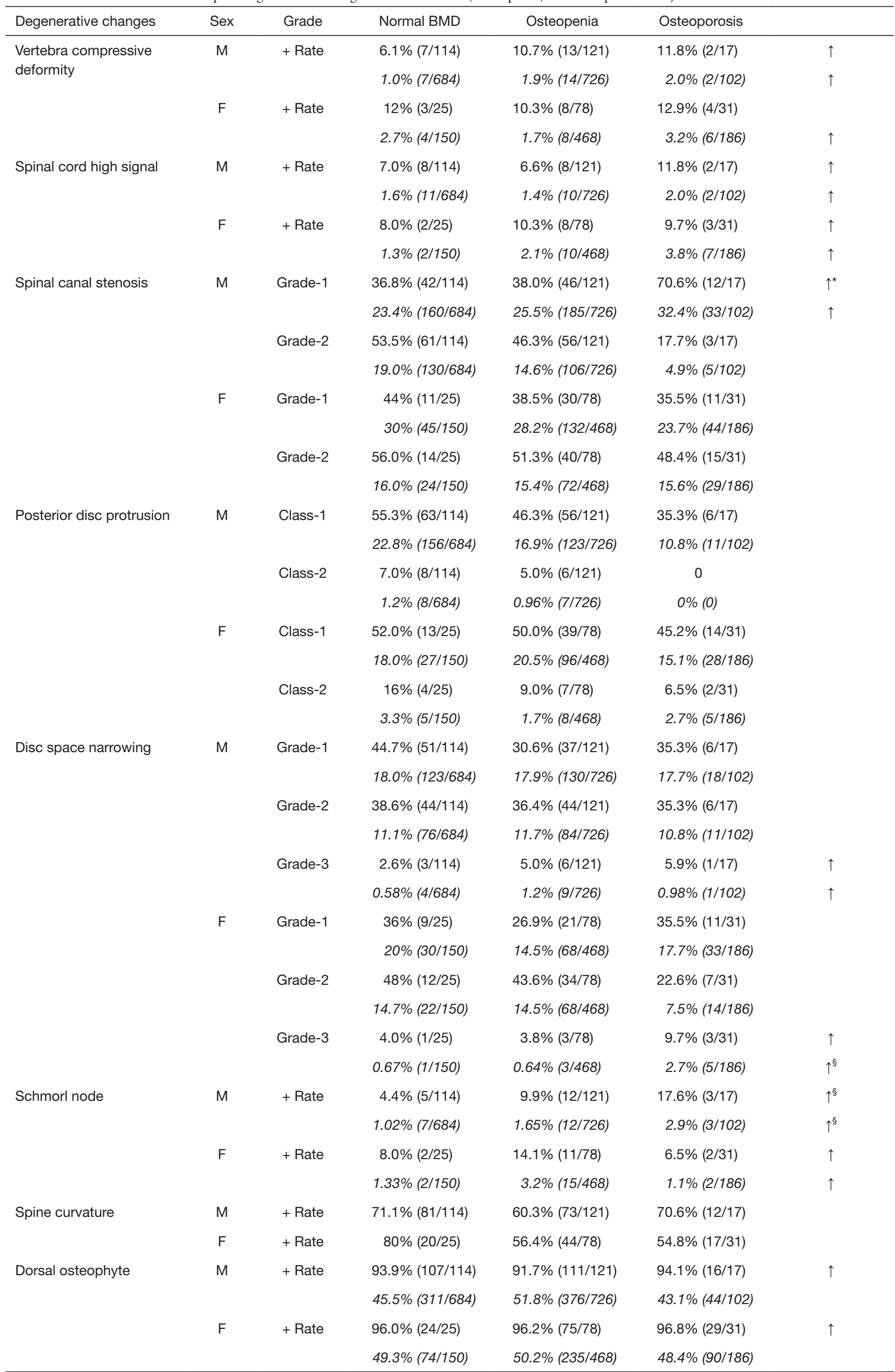

+ Rate, prevalence of the positive findings for degeneration; $\uparrow$, a trend of the lower BMD groups have higher cervical spine degenerative change prevalence; * $\mathrm{P}<0.05 ;{ }^{\S}, \mathrm{P}<0.1$. Cells in italic: results as 'by-intervertebral-level'. BMD, bone mineral density. 